\title{
FICÇÃO E POLÍTICA EM TEMPO DE GUERRA: O PROJETO TRADUTÓRIO ESTADUNIDENSE PARA A LITERATURA BRASILEIRA (1943-1947)
}

Fiction and politics during wartime: the North-American translation project for the Brazilian literature (1943-1947)

Ficción y política en tiempos de guerra:

el proyecto de traducción estadunidense para

la literatura brasileńa (1943-1947)

ELIZA MITIYO MORINAKA

http://dx.doi.org/10.1590/S2178-14942017000300008

Eliza Mitiyo Morinaka é mestre em Letras (Inglês e Literatura Correspondente) pela Universidade Federal de Santa Catarina (UFSC) e doutora em Literatura e Cultura pela Universidade Federal da Bahia (UFBA) com a tese intitulada Política cultural e jogos de poder na tradução da narrativa de ficção brasileira traduzida nos Estados Unidos (1943-1947), defendida em março de 2017. É professora do Departamento de Letras Germânicas da UFBA. Este artigo recebeu apoio da Coordenação de Aperfeiçoamento de Pessoal de Nível Superior (CAPES) na forma de bolsa de doutorado sanduíche realizado na Georgetown University, em Washington D.C., Estados Unidos, em 2015 (eliza_morinaka@yahoo.com.br).

Artigo recebido em 25 de maio e aprovado para publicação em 30 de agosto de 2017. 


\title{
RESUMO
}

0 objetivo deste artigo é analisar os projetos do Office of the Coordinator of Inter-American Affairs e seus colaboradores para a tradução da narrativa de ficção brasileira para o inglês no período de 1943 a 1947. Demonstrarei que esse projeto tinha um caráter pedagógico e produziu uma representação de Brasil agrário e atrasado em contraste com os Estados Unidos industrializados e modernos. Para fazê-lo, analisei os documentos do Departamento de Estado dos EUA, da American Library Association, do American Council of Learned Society e do arquivo pessoal de um dos tradutores participantes do projeto, Dudley Poore.

PalaVRAS-CHAVE: literatura brasileira; projetos de tradução; relações Brasil-Estados Unidos.

\begin{abstract}
This article analyses the translation project of Brazilian novels in the United States between 1943 and 1947 devised by the Office of the Coordinator of Inter-American Affairs. I will demonstrate that the project's pedagogical purpose foregrounded the representation of an agrarian and backward Brazil, which contrasted with the industrialised and modern United States. In order to do it analyse documents of the US State Department, the American Library Association and the American Council of Learned Society, and the personal papers of Dudley Poore, one of the translators who worked in the project.
\end{abstract}

KEY-WORDS: Brazilian literature; translation project; Brazil-United States relations.

\section{RESUMEN}

El objetivo de este artículo es analizar los proyectos del Office of the Coordinator of Inter-American Affairs y sus colaboradores para la traducción para el inglés de la narrativa de ficción brasileña durante el período entre 1943 y 1947. Demostraré que ese proyecto tenía un carácter pedagógico y produjo una representación de Brasil agrario y atrasado en contraste con los Estados Unidos industrializado y moderno. Para hacer-lo, analicé los documentos del Departamento de Estado de los EUA, de la American Library Association y del American Council of Learned Society, y el archivo personal de uno de los traductores participantes del proyecto, Dudley Poore.

Palabras Clave: literatura brasileña; proyectos de traducción; relaciones Brasil-Estados Unidos. 


\section{A}

tradução da narrativa de ficção brasileira para a língua inglesa data de pelo menos 1886, quando foram oferecidos aos leitores os romances Iraçéma: the honey-lips (a legend of Brazil) e Manuel de Moraes, ambos publicados em um único volume pela Bickers \& Son, de Londres. A primeira tradução foi assinada por Isabel Burton e a segunda por ela e seu marido, Richard Francis Burton. No século XX, a tradução de romances iniciou-se em 1920, com a publicação de Canaan, realizada por Mariano Joaquín Lorente, tendo como texto de partida Canaã (1902), de Graça Aranha. Em 1921, Iracema (1865) ganhou uma retradução em inglês, dessa vez feita por Norman Biddel. Em 1926, a tradução de Harry W. Brown de $O$ cortiço (1890), de Aluísio Azevedo, foi publicada como A Brazilian tenement. Além desses romances, três coletâneas de contos brasileiros traduzidos foram publicadas: Mapirunga (1924), de Gustavo Barroso, Urupês (1925), ${ }^{1}$ de Monteiro Lobato, e Brazilian Tales, reunindo histórias de Machado de Assis, José Medeiros e Albuquerque, Coelho Neto e Carmem Dolores. Na década de 1930, o público assistiu à chegada de apenas dois romances brasileiros em tradução, um de Mário de Andrade, Amar, verbo intransitivo (1927), e o outro de Paulo Setúbal, A marquesa de Santos (1925), e de uma crônica de Luiz Edmundo, O Rio de Janeiro no tempo dos vice-reis (1932). Com exceção de Mapirunga, as traduções das décadas de 1920 e 1930 foram publicadas primeiramente nos Estados Unidos e em seguida na Inglaterra.

Na década de 1940, especificamente nas traduções levadas ao público pelas editoras estadunidenses, adicionou-se o componente político ao interesse pela nossa literatura, que acabou se transformando em um dos bens simbólicos apropriados pelos projetos culturais do governo dos EUA durante a Segunda Guerra Mundial (1939-1945). O Office of the Coordinator of Inter-American Affairs (OCIAA), órgão responsável pelas relações com os países latino-americanos, elaborou e executou as ações de intercâmbio cultural para fortalecer os laços de 'amizade' entre as Américas. ${ }^{2}$ Além dos acordos de interesse político e econômico, - OCIAA ressaltou as atividades culturais para garantir uma inserção estadunidense mais efetiva nos países vizinhos. Tota (2000: 41) referiu-se ao Office como "uma verdadeira fábrica

\footnotetext{
${ }^{1}$ Destaque-se que a versão em língua inglesa de Urupês foi intitulada Brazilian short stories e incluiu três traduções dos 14 contos do texto fonte: 'Um suplício moderno', 'O engraçado arrependido' e 'O comprador de fazendas'.

2 Para informações sobre a história do OCIAA no Brasil e suas atividades, cf. Tota (2000); para referências gerais sobre 0 OCIAA, cf. Espinosa (1976), Guerrant (1950) e United States (1947).
} 
de ideologias". Em curto prazo, os programas de rádio alcançaram um grande público para difundir os ideais do governo dos EUA e combater a propaganda alemã e italiana, que já se espalhara pelo território nacional também pelas ondas dos rádios. Concomitantemente, outros projetos com o mesmo objetivo foram colocados em prática, tais como a produção de curtas-metragens, desenhos animados, propagandas de produtos estadunidenses em revistas e publicação das revistas Em Guarda e Seleções (uma versão da Reader's Digest).

Implementados a passos mais lentos, devido às dificuldades econômicas relacionadas ao preço do papel, aos direitos autorais e às leis de importação e exportação, os projetos de tradução de livros brasileiros também tiveram seu lugar nessa estratégia de "sedução" (terminologia de Tota). Obviamente, o programa não poderia ser escancaradamente uma via de mão única. Também seria conveniente que os EUA conhecessem melhor a cultura de seus vizinhos por meio de sua literatura.

A influência cultural estadunidense no Brasil já se configurou como importante objeto de estudo para alguns pesquisadores, como Gerson Moura (1984), que abordou a influência cultural estadunidense no Brasil durante a Política da Boa Vizinhança, Pedro Tota (2000), que reconstituiu o histórico do OCIAA no Brasil, Luciano Klöckner (2008), que pesquisou o programa de rádio Repórter Esso como produtor de sentidos por meio das propagandas político-ideológicas durante a Segunda Guerra e a Guerra Fria, Darlene Sadlier (2012), que analisou a engrenagem cultural do OCIAA, debruçando-se particularmente sobre os filmes e as artes plásticas brasileiras, e Laura de Oliveira (2015), que analisou o programa editorial da GRD, do integralista Gumercindo Rocha Dorea, que divulgou material de cunho anticomunista no período anterior ao golpe civil-militar no Brasil de 1964, financiado pelos EUA. A primeira diferença contida em meu estudo é que ele está centrado em uma dimensão inexplorada por esses historiadores, isto é, a literatura brasileira traduzida para o inglês nos anos 1940.

Na área de Estudos da Tradução, especificamente, algumas pesquisas já trataram das narrativas de ficção em língua inglesa traduzidas no Brasil, a exemplo dos livros de José Paulo Paes (1990), que traçou um histórico da tradução literária no Brasil; John Milton (2002), que pesquisou o Clube do Livro no Brasil, focando as traduções das literaturas de língua inglesa; e Irene Hirsch (2006), que estudou as traduções de autores de ficção em prosa estadunidenses do século XIX no Brasil. Aqui está a segunda novidade de minha pesquisa, já que faço o caminho inverso, ou seja, ocupo-me da narrativa de ficção brasileira traduzida para os EUA na década de 1940 e suas representações no contexto estadunidense.

0 objetivo deste artigo é analisar os projetos engendrados pelo OCIAA e seus colaboradores, visando a tradução da narrativa de ficção brasileira para o inglês no período de 1943 a 1947. A publicação das traduções por si não seria suficiente para conseguir despertar 
o interesse dos leitores pelos desconhecidos escritores brasileiros, não fossem também outros projetos, que, em uma rede bem sincronizada entre ações, governo, instituições, burocratas e intelectuais, abriram o caminho para a divulgação da língua portuguesa e a expressão literária do Brasil. Demonstrarei que esse rigoroso controle da 'indústria das traduções' pelo Departamento de Estado, que envolveu intelectuais dos dois países, imprimiu um caráter pedagógico à literatura brasileira, aproveitando-se o momento em que os cidadãos médios estadunidenses buscavam se instruir sobre outros países. Ao mesmo tempo, a representação agrária e hostil do Brasil das narrativas regionalistas foi delineada como um ponto de contraste da industrialização e da modernização dos Estados Unidos. Alicerçava-se, no plano imaginário, o imprescindível papel estadunidense na liderança das Américas.

Para demonstrar a hipótese acima, realizei uma ampla pesquisa e análise de centenas de documentos referentes aos projetos de tradução propostos pelo OCIAA e as editoras estadunidenses. Essa documentação está depositada em mais de trezentas caixas do Grupo 229 - 'Inter-American Affairs', no National Archives II, em College Park (MD), e é formada por correspondências, memorandos, relatórios e atas de reuniões. À medida que encontrava as informações e montava o quebra-cabeça do projeto tradutório a partir da leitura dessas fontes, iniciei a busca pelos arquivos das instituições executoras de algumas atividades. Portanto, incluí em minha investigação o exame de outros três conjuntos de fontes: os documentos da American Library Association (ALA), depositados nos University of Illinois Archives, em Urbana-Champaign (IL); a documentação do American Council of Learned Societies (ACLS), na Manuscript Division da Biblioteca do Congresso, Washington D.C.; e, finalmente, o arquivo pessoal de Dudley Poore, tradutor de A fogueira, da Beinecke Rare Book and Manuscript Library, na Yale University Library, em New Haven (CT).

0 quinto e último conjunto de fontes de minha pesquisa é formado pelos livros que foram efetivamente traduzidos do português para o inglês. No levantamento que fiz na Biblioteca do Congresso dos Estados Unidos e na Biblioteca Britânica pude corrigir e atualizar os catálogos existentes, contabilizando um total de 209 obras de ficção em prosa traduzidas ao longo do século XX. Neste artigo examinarei nove títulos traduzidos no contexto da Segunda Guerra Mundial.

0 primeiro livro brasileiro traduzido nessa década aparece nominalmente nos documentos do fundo 'Inter-American Affairs': Caminhos cruzados (1935), de Érico Veríssimo. A versão em inglês, feita por Louis C. Kaplan e intitulada Crossroads, foi publicada em 1943. Em 1944, Os Sertões (1902), de Euclides da Cunha, e A fogueira (1942), de Cecílio Carneiro, chegaram às prateleiras estadunidenses como Rebellion in the backlands, traduzido por Samuel Putnam, e The bonfire, vertido por Dudley Poore, respectivamente. Em 1945, publicou-se a tradução de Terras do sem fim (1943), de Jorge Amado, intitulada The violent land, de autoria de Samuel Putnam. E, 
em 1946, foi a vez de Angústia (1936), de Graciliano Ramos, traduzido como Anguish por Louis C. Kaplan. Para essas obras, encontrei os respectivos projetos tradutórios.

Contudo, outras traduções em inglês foram publicadas nos anos 1940 sem que eu tenha localizado registros das negociações para sua produção: A Amazonia mysteriosa (1925), de Gastão Cruls, traduzido como The mysterious Amazonia (1944) por Joseph Sadler; Inocência (1872), do Visconde de Taunay, que teve mantido o título Inocência (1945), traduzido por Henriqueta Chamberlain; O resto é silêncio (1943), de Érico Veríssimo, vertido como The rest is silence (1946); e Olhai os lírios do campo (1938), de Érico Veríssimo, traduzido como Consider the lilies of the field (1947) por Jean Neel Karnoff. Apesar da participação de Érico Verissimo, de Henriqueta Chamberlain e da Macmillan nos projetos tradutórios, não encontrei nenhuma documentação relacionada diretamente a esses títulos.

\section{CONCEPÇÃO E FUNCIONAMENTO DO PROJETO DE TRADUÇÃO}

$\mathrm{O}$ s livros de ficção, a rigor, não poderiam ser publicados pela editora do governo dos Estados Unidos porque seria um processo demasiadamente burocrático e longo, sem contar que guardaria semelhanças com o mecenato das artes na Idade Média. 0 controle da literatura pelo Estado, principalmente em um país onde as liberdades de expressão e de imprensa estão consignadas no primeiro artigo da Constituição, seria vista, no mínimo, como algo suspeito. Então, para maior agilidade e garantia de uma aparência de lisura, optou-se por recorrer a editoras privadas ou universitárias, que, por sua vez, não poderiam ter prejuízos em tempos difíceis como aqueles. 0 governo repassaria os recursos financeiros por meio dos projetos do OCIAA.

O projeto guarda-chuva apresentado pela Divisão de Imprensa do OCIAA, intitulado Tradução da literatura de outras Américas para o inglês, contemplaria a tradução de livros "de excelência de outras Repúblicas Americanas", com a finalidade de aperfeiçoar o conhecimento sobre os vizinhos. Tal tarefa ficaria nas mãos de "editoras comerciais e universitárias com boa reputação" que se disponibilizassem a assumir os custos da publicação, divulgação e distribuição, pois o subsídio se destinaria exclusivamente à tradução. Devido à pouca projeção dos livros das "outras Repúblicas" nos EUA, o projeto estimularia a leitura dos "livros mais importantes" em espanhol e português e de "outras Américas". A tradução possibilitaria um novo mercado para esses escritores e apoiaria a causa literária para o entendimento interamericano. Em 1942 foram alocados para o projeto 30 mil dólares, valor que deveria ser gasto com a tradução de aproximadamente 25 livros. $^{3}$

\footnotetext{
${ }^{3}$ National Archives and Records Administration II (NARA II). RG229, Office of Inter-American Affairs (OIAA). Project authorizations, 1942-1945. Letter Archives, Box 538.
} 
A Unidade de Publicações, por meio de conselheiros indicados pelo American Council of Learned Societies (ACLS), ficaria encarregada da primeira etapa, concernente à escolha dos títulos a serem traduzidos. Após a seleção, a Comissão Mista, composta por representantes do OCIAA, do ACLS e do Departamento de Estado, decidiria sobre sua aprovação ou não. Outros livros poderiam ser adicionados de tempos em tempos, conquanto tramitassem da mesma maneira que os anteriores. 0 Departamento de Estado se constituiria na última instância, encarregada de chancelar os livros pré-selecionados para a tradução, fato comprovado pelas várias correspondências entre o OCIAA e a Comissão Mista. Tal prática distanciava-se da isenção do governo e da total autonomia intelectual defendida nos discursos das autoridades e representantes do OCIAA. Harry Frantz, diretor da Divisão de Imprensa, por exemplo, ao aprovar a continuidade do projeto de intercâmbio de livros e revistas conduzido pela Comissão de Relações Culturais com a América Latina, Inc., argumentou que o governo não poderia atuar diretamente no campo intelectual, pois materiais estritamente literários seriam "suspeitos se vindos de quaisquer órgãos governamentais". ${ }^{4}$ Archibald MacLeish, bibliotecário do Congresso, na discussão sobre a elaboração da revista Literary Review, também já antecipara sua preocupação com o controle e a supervisão da publicação de uma revista literária pelo governo e a possível dissonância com as editoras. ${ }^{5}$

Para contornar a "suspeita" de qualquer agenda política subjacente às publicações e seguir o princípio de liberdade intelectual que fundamentava as relações culturais, o Departamento de Estado criou uma fachada para o exercício de uma pseudoliberdade. Designou, assim, alguns institutos para executar a tarefa, o ACLS, a Inter-American Educational Foundation Inc. (IAEF), a Hispanic Foundation (HF), sediada na Biblioteca do Congresso, a Universidade do Texas, a Universidade de Chicago, e editoras comerciais como a Alfred Knopf, MacMillan, Viking Press, Farrar \& Strauss, entre outras. Apesar de contar com o subsídio do Departamento de Estado, via OCIAA, as instituições (supostamente) teriam autonomia para constituir as equipes ou comissões de trabalho, determinar as diretrizes desde a concepção até a execução, e selecionar os livros que estivessem de acordo com seus interesses intelectuais, estéticos, acadêmicos ou de mercado. A partir dessas orientações gerais detalhadas no projeto guarda-chuva, cada instituto, editora comercial ou universitária poderia apresentar uma proposta para a apreciação do OCIAA. No entanto, a chancela final seria dada pelo Departamento de Estado.

Um dos primeiros projetos submetidos ao OCIAA, intitulado Tradução de romances sul-americanos para o inglês, das editoras Viking Press e Macmillan Company, sediadas em Nova York, solicitava o subsídio para a tradução. Alegando dificuldades para inserir os livros

\footnotetext{
${ }^{4}$ NARA II. RG229, OIAA. Department of Press and Publications: General records, 1941-1945. Legal Archives. Box 1470. ${ }^{5}$ NARA II. RG353, Records of Interdepartmental and Intradepartmental Committees (State Department). The interdepartmental committee on cooperation with American Republics. Minutes of meetings, Box 29. Ata da reunião de 17 e 18 set. 1941.
} 
latino-americanos no mercado comercial sem um incentivo financeiro, as editoras requisitavam o custeio para a tradução e a editoração dos manuscritos. A Viking Press se encarregaria de traduzir Jimenez de Quesada, de German Arciniegas, que fora publicado em 1939 para coincidir com as comemorações dos 400 anos da fundação de Bogotá, e a Macmillan se comprometeria com a tradução de três livros: La quintrala (1931), de Magdalena Petit, que ganhou o prêmio do jornal La Nacion; Chile: una loca geografia (1940), de Benjamin Subercasceux; e Caminhos cruzados (1936), do brasileiro Érico Veríssimo, que fora traduzido para o inglês por Louis C. Kaplan com o título Crossroads, e cuja versão fora lida e aprovada por Hershell Brickell.

Os custos da edição da tradução, impressão, divulgação e distribuição dos romances ficariam totalmente a cargo das editoras. O OCIAA arcaria somente com o subsídio da tradução, que não poderia exceder o valor de quinhentos dólares por romance. A Divisão de Relações Culturais carimbou a aprovação de todos os títulos por representarem uma combinação de qualidade literária, adequação ao mercado estadunidense e representação das tendências literárias das outras repúblicas americanas. Em seu parecer, John P. Bishop declarou que o projeto fora preparado de acordo com a política adotada para o subsídio de livros sul-americanos de importância, os quais, "sem a nossa ajuda, certamente não apareceriam aqui". Todos esses livros haviam sido muito bem recomendados, e ele se mostrou esperançoso de um razoável sucesso nos EUA. ${ }^{6}$ Em fevereiro de 1942 iniciaram-se as negociações das cláusulas do contrato com cada editora, e após vários acertos e modificações ${ }^{7}$ assinou-se o documento entre 0 OCIAA e a MacMillan, estipulando-se o pagamento de quatrocentos dólares para a tradução de Caminhos cruzados, contanto que a tiragem da primeira edição não fosse inferior a 2.500 cópias. ${ }^{8}$ Finalmente, em 1943, Crossroads foi o primeiro romance brasileiro a ser traduzido sob a tutela do projeto de tradução encaminhado ao Departamento de Estado.

Outro projeto, intitulado Estudo da vida e da cultura brasileira, proposto pelo Departamento de Estado, cogitou apresentar um "autorretrato do caráter brasileiro" e previu a preparação de um livro que "sintetizasse a vida e a cultura brasileira", incluindo textos selecionados das melhores obras literárias de referência de escritores brasileiros. William Lytle Schurz, ${ }^{9}$ chefe temporário das relações culturais, revelou a crença de que tal tipo de trabalho, "de caráter não

\footnotetext{
${ }^{6}$ NARA II. RG229, OIAA. Education division: project files, 1941-1950. Letter Archives, Box 1174. Memorando de John Bishop para George Dudley, 15 nov. 1941.

${ }^{7}$ NARA II. RG229, OIAA. Education division: project files, 1941-1950. Letter Archives, Box 1174. Correspondências trocadas entre o OCIAA e a MacMillan em 1942.

${ }^{8}$ NARA II. RG229, OIAA. Project authorizations, 1942-1945. Letter Archives, Box 538.

${ }^{9}$ Schurz foi professor de história econômica e trabalhou para o governo de Roosevelt no Conselho de Segurança Social e 0 governo de Hoover como adido comercial no Brasil. Disponível em: <http://oasis.lib.harvard.edu/oasis/deliver/ hou02218>. Acesso em 9 out. 2015.
} 
somente literário, mas também popular", seria uma "contribuição genuína" para as relações Brasil-EUA, aventando a possibilidade de sua tradução também para o espanhol. ${ }^{10}$

Os critérios para a seleção dos títulos obedeceriam às seguintes características:

i) a psicologia do caráter nacional, ii) seu condicionamento determinado pela geografia humana e pelas tradições de vida, iii) sua mais expressiva característica atual, seja na arquitetura, na ficção regional ou na análise social, e iv) o caráter emergente e suas transformações desde 1920: os problemas constantes, os efeitos predominantes e os esforços aparentes. ${ }^{11}$

Tal proposta surgiu a partir de uma viagem de estudo de seis meses da senhora Dorothy M. Wilmotte ${ }^{12}$ pelo Brasil em 1939, ocasião em que participou de várias conferências com líderes literários que sugeriram as várias maneiras de os EUA conhecerem os brasileiros. 0 trabalho seria conduzido por um coeditor brasileiro, selecionado por Wilmotte e com a aprovação do Departamento de Estado e o OCIAA, que auxiliaria na seleção do material e o direcionaria para os tradutores. A tradução e a edição, previstas para maio de 1942, com lançamento no outono do mesmo ano, custariam três mil dólares.

Não há informações sobre o produto final no projeto apresentado ao OCIAA, se seria uma antologia contendo contos ou capítulos de romances, ou se seriam vários romances avulsos traduzidos. A anotação no relatório de atividades do OCIAA no Brasil esclareceu parte dessa dúvida: 0 projeto recebeu o subsídio, e a Sra. Wilmotte deu continuidade à seleção de textos para a antologia, finalizada de acordo com o previsto, em 1942 (UNITED STATES, 1943). Porém o relatório não especifica o título da antologia. Ao sondar o arquivo de Dudley Poore, localizei correspondências suas com William Lytle Schurz. Essa documentação epistolar indica que Fiesta in November (título homônimo da tradução do romance Fiesta en Noviembre, de 1938, do escritor argentino Eduardo Mallea), era a antologia à qual se referia o projeto, editada por Dudley Poore e Angel Flores em 1942. ${ }^{13}$ Ao folhear o volume, notei que havia somente um texto representando o Brasil, um capítulo do romance Mar Morto, de Jorge Amado, traduzido como Sea of the dead, por Donald Walsh. ${ }^{14}$ Ou

\footnotetext{
${ }^{10}$ NARA II. RG229, OIAA. Project authorizations, 1942-1945. Letter Archives, Box 536.

${ }^{11}$ Minha tradução de: "i) The psychology of the national character; ii) Its conditioning by human geography and by the living tradition; iii) Its most characteristic expression today - whether in architecture, regional fiction, social analysis; iv) The emerging character, content and rate of changes since 1920: persistent problems, prevailing purposes and conspicuous efforts." 12 Não há informações adicionais sobre essa personagem em nenhum outro documento ou livro.

${ }^{13}$ Beinecke Rare Book and Manuscript Library, Yale Collection of American Literature (YCAL), MSS 559. Dudley Poore Papers, Box 8. Correspondência de William Schurz a Dudley Poore, 26 maio 1944.

${ }^{14} \mathrm{O}$ capítulo de Mar Morto incluído na coletânea é uma tradução de segunda mão. O pessoal do OCIAA não conseguiu enviar o livro do Brasil, e tampouco encontrou um exemplar em Nova York ou Washington. Por absoluta falta de tempo, apesar de Dudley mostrar-se contrário a essa prática, Walsh teria que trabalhar com a edição em espanhol, Mar Muerto (1940), traduzida por Benjamín de Garay e publicada na Argentina (YCAL, MSS 559. Dudley Poore Papers, Box 9. Correspondência de Dudley Poore para Donald Walsh, 20 out. 1941.)
} 
seja, o que seria a princípio um estudo da vida e da cultura brasileira acabou reunindo contos ou trechos de romances da Argentina (três textos), Equador (um), Peru (dois), Colômbia (um), Venezuela (dois), México (um), Uruguai (um), Panamá (um) e Chile (quatro).

O OCIAA não parece ter se importado com o aparente desvio dos recursos originalmente disponibilizados para o projeto de um "autorretrato do caráter brasileiro" que "sintetizasse a vida e a cultura brasileira" por meio das melhores obras literárias de referência de "escritores brasileiros". As correspondências trocadas entre Poore e Schurz mencionam o produto final do projeto, Fiesta in November, indicando a importância de iniciativas como essas para melhorar a relação Brasil-EUA. De qualquer maneira, se eliminarmos a marcação temporal explicitada no projeto, as características almejadas para a seleção dos textos parecem encaixar-se, cada qual à sua maneira, nos romances brasileiros traduzidos nos anos 1940.

A editora Farrar \& Rinehart e a revista Redbook Magazine submeteram um projeto ao OCIAA solicitando auxílio para um concurso intitulado Prêmio para autores sul-americanos. A premiação tinha como meta incentivar autores latino-americanos a procurar um público nos Estados Unidos. Em 1940 e 1942, essas firmas, em cooperação com a Pan American Union, já haviam realizado um concurso literário. 0 comitê responsável pela seleção foi integrado por críticos e escritores, e contou com os nomes mais significativos de cada república latino-americana. Já a comissão julgadora internacional incluiu personalidades como John Dos Passos, Ernesto Montenegro e Blair Niles. Ciro Alegria, do Peru, recebeu o primeiro prêmio por Broad and alien in the world, e as menções honrosas foram concedidas a E. Gil Gilbert, do Equador, por Our daily bread, Cecilio J. Carneiro, do Brasil, por The bonfire, e a Miguel A. Menendez, do México, por Nayar. Os relatórios recebidos da América Latina indicavam que o prêmio "fez um sucesso extraordinário" no estreitamento das relações culturais entre as Américas. ${ }^{15}$ Além da premiação, os livros foram vertidos para o inglês e publicados pela Farrar \& Rinehart. Harriet de Onís traduziu Broad and alien in the world em 1941, Dudley Poore verteu Our daily bread em 1943 e The bonfire em 1944, e Angel Flores, Nayar, em 1942.

Terras do sem fim (1943), de Jorge Amado, concorreu à premiação dessa nova edição, conforme indicação na orelha da sua primeira publicação pela Livraria Martins Editora. 0 romance fora escolhido por uma:

[...] comissão composta pelos srs. Manuel Bandeira, Álvaro Lins e Prudente de Morais Neto para representar a ficção brasileira no concurso de romances inter-americanos, realizado nos Estados-Unidos e que, simultaneamente com este, sai numa edição norte-americana do editor Knopf, de Nova-lorque (Amado, 1943).

${ }^{15}$ NARA II. RG229, OIAA. Project authorizations, 1942-1945. Letter Archives, Box 530. 
Somando-se aos projetos de tradução, Cecil Cross, cônsul geral dos EUA no Brasil, atuou como porta-voz do valor da literatura brasileira e do comprometimento que os "americanos" deveriam ter para "honrar as letras e as artes brasileiras" ${ }^{16}$ A documentação epistolar de Cecil Cross com o secretário de Estado menciona o envio de vários livros brasileiros para conhecimento do Departamento de Estado. Em 1 de março de 1944, Cross enviou cinco cópias do livro Obras primas da lírica brasileira, de Manuel Bandeira e Edgar Cavalheiro. ${ }^{17}$ Em uma remessa anterior, Cross enviara duas cópias de Laís e Salomé, de Menotti del Picchia, juntamente com uma pequena biografia e bibliografia do escritor, conforme a Figura 1:

\section{Figura 1: Correspondência de Cecil Cross com o secretário de Estado ${ }^{18}$}
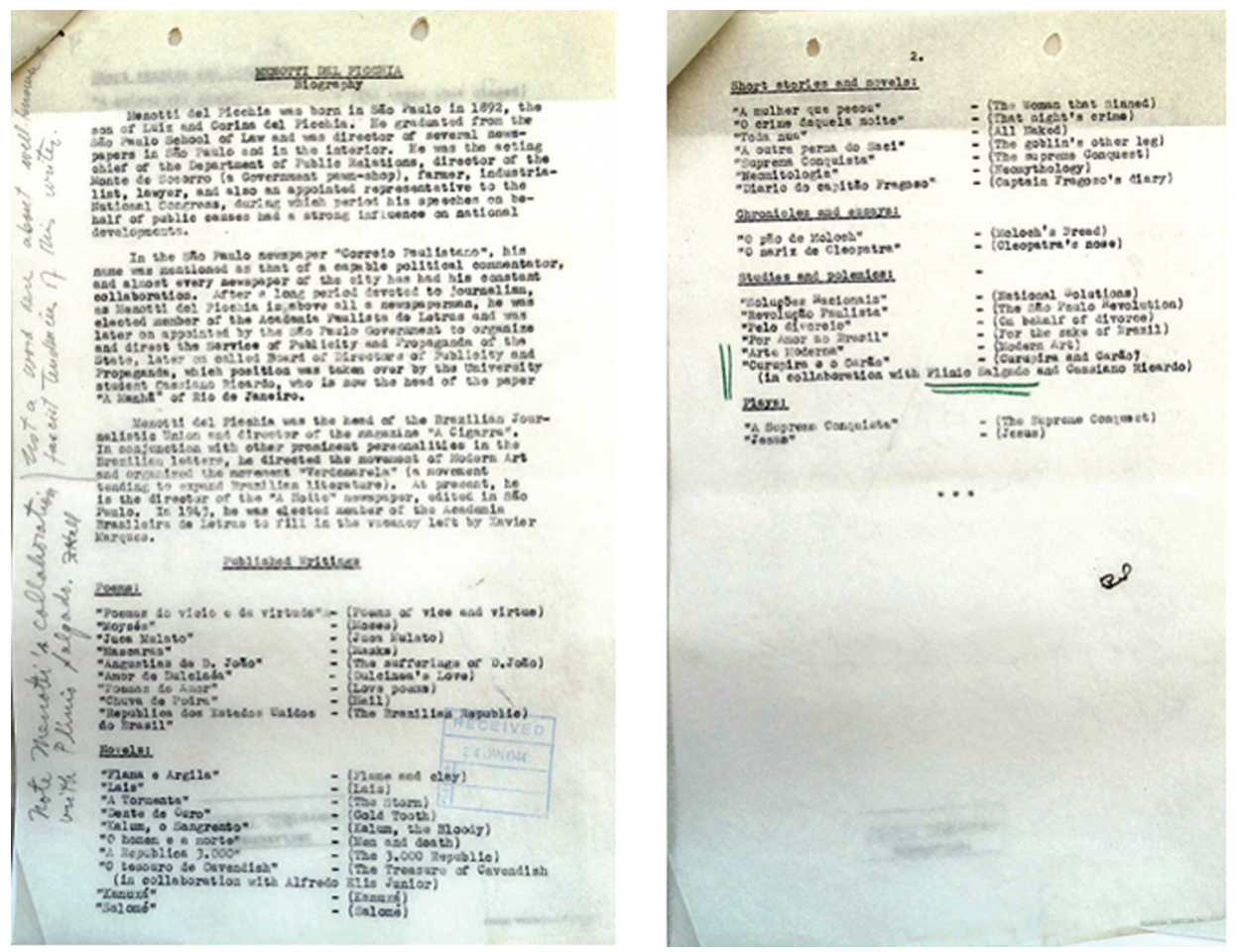

Fonte: NARA II. RG229, Office of Inter-American Affairs

${ }^{16}$ NARA II. RG229, OIAA. Regional Division (RD), Coordination committee for Brazil (CCB): General Records (GR), 1941 1945. Legal Archives, Box 1330. Correspondência de Cecil Cross para o Secretário de Estado. São Paulo, 29 set. 1944.

17 NARA II. RG229, OIAA. RD, CCB: GR, 1941-1945. Legal Archives, Box 1330. Correspondência de Cecil Cross para o Secretário de Estado. São Paulo, 1 mar. 1944.

${ }^{18}$ NARA II. RG229, OIAA. RD, CCB: GR, 1941-1945. Legal Archives, Box 1330. Correspondência de Cecil Cross para 0 Secretário de Estado. São Paulo, 20 jan. 1944. 
Nota-se que, na margem esquerda da primeira página, há uma anotação, como se observa mais claramente na imagem expandida da Figura 2:

Figura 2: Anotação à margem da carta de Cecil Cross ao Secretário de Estado

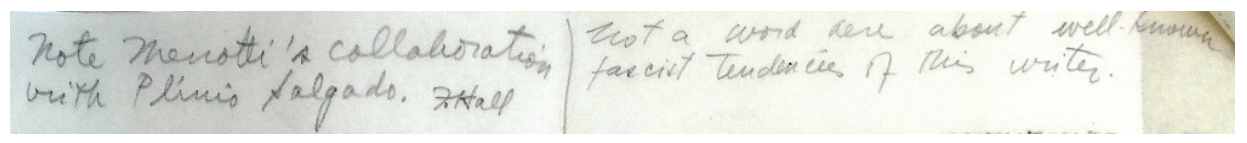

Fonte: NARA II. RG229, Office of Inter-American Affairs

A anotação a lápis à esquerda chama a atenção para a colaboração de Menotti del Picchia com Plínio Salgado, referindo-se ao grifo em verde na segunda página da correspondência (cf. Figura 1), onde se vê destacada a coautoria do integralista Plínio Salgado e do escritor Cassiano Ricardo no livro Curupira e o Carão. Já a anotação à direita traduz-se como: "nenhuma palavra aqui sobre as conhecidas tendências fascistas desse escritor" (minha tradução).

Cassiano Ricardo, Menotti Del Picchia e Cândido Mota Filho, atuantes do movimento verde-amarelo do Modernismo brasileiro na década de 1920, estavam à frente, ao lado de Lourival Fontes, do Departamento de Imprensa e Propaganda (DIP) (Veloso, 1987), órgão onde - OCIAA foi abrigado no país. Porém nenhum de seus romances, ensaios ou poesias foram traduzidos nesse projeto. Apesar de, na década de 1930, já terem tomado rumos diferentes dos do integralista Plínio Salgado, fortemente influenciado pelo fascismo, seus nomes estariam para sempre marcados e associados a esse tronco ideológico e político, devido às publicações que haviam feito em conjunto no passado. Isso fortalece a hipótese de as escolhas e decisões sobre os textos para tradução dependerem fortemente do escritor e suas posições políticas, e não somente da importância ou da qualidade estética dos textos propriamente ditos. Se houve um breve afrouxamento no controle da circulação de escritores com ideias comunistas nos Estados Unidos, o mesmo não aconteceu com escritores simpatizantes dos regimes totalitários, pois a luta contra o avanço nazifascista na Europa era uma das bandeiras levantadas pelos Aliados e deveria ser encampada com a maior urgência.

0 programa de tradução de livros iniciou-se com a transferência de fundos para 0 ACLS. Quando parte das atividades culturais do OCIAA transferiu-se para o Departamento de Estado, o Conselho já tinha assinado o contrato para a tradução de 116 livros. Até o final de 1943 já haviam sido publicados 57, e o restante ficaria para o ano seguinte (Espinosa, 1976: 220). Cerraram-se, assim, as cortinas do Departamento do Estado, órgão que muito trabalhou e gastou para forjar uma 'amizade', estendendo seus braços (ou tentáculos) e tomando decisões sobre a produção artística e cultural a fim de seduzir as elites e os intelectuais dos países sul-americanos como aliados. 
Apesar da pouca experiência de diplomacia cultural do governo estadunidense na Segunda Guerra, as ações executadas nas Américas durante a Política da Boa Vizinhança funcionaram como uma espécie de incubadora para inspirar futuros planos para a diplomacia cultural. Os projetos do OCIAA voltados para a sedução das elites intelectuais latino-americanas abarcaram as artes plásticas, a literatura e a música. De interesse para o presente artigo são os livros, apresentados a seguir como um centro em torno do qual se situaram outros projetos com o objetivo de criar um público e preparar um caminho para a recepção da literatura latino-americana.

\section{ESTRATÉGIAS PARA A DIVULGAÇÃO DA CULTURA E DA FICÇÃO BRASILEIRA: PROJETOS SATÉLITES}

a década de 1940 não se encontravam livros técnicos, científicos ou acadêmicos das
Américas do Sul e Central no mercado dos Estados Unidos, mas um cenário diferente se configurava para os livros de ficção. No caso da literatura brasileira, especificamente, alguns títulos traduzidos para o inglês podem até mesmo ter circulado modestamente por lá, apesar de publicadas por editoras britânicas. Alguns poemas e contos que apareceram em antologias ou periódicos sobre a América Latina engrossaram um pouco o corpo da literatura brasileira conhecida nos círculos estritamente acadêmicos. Como, então, fazer com que cidadãos estadunidenses se interessassem por livros das novas nações 'amigas' com que uniam forças para a solidariedade hemisférica? Como preencher a lacuna do desconhecimento da língua, da cultura, da geografia e da história sobre esses países em um curto espaço de tempo? E talvez, o mais desafiador de tudo, como criar um hábito de consumo para esses produtos das novas culturas?

Os caminhos que atingiram rapidamente uma grande quantidade de pessoas foram, sem dúvida, as ondas de rádio, por meio da seleção musical e de entrevistas com personalidades da América Latina, e as imagens do cinema, com a produção de documentários sobre os costumes, as pessoas, a fauna e a flora, até então desconhecidos da população estadunidense. No âmbito das publicações, a Divisão de Imprensa empregou um grande número de pessoas na fábrica de notícias sobre a América Latina. Um esquema bem estruturado e eficiente facilitou a rede de troca de clippings entre o Office em Washington e as regionais para abastecer os jornais com as notícias. E os livros? Quais seriam os caminhos possíveis?

Para garantir a efetividade das traduções como veículos de divulgação da cultura latino-americana, o subsídio governamental abarcou os seguintes programas: i) a formação de uma associação de editoras; ii) a circulação de livros e revistas latino-americanos nas 
bibliotecas e universidades; iii) a distribuição de prêmios literários; iv) o fortalecimento dos centros de estudos latino-americanos nas universidades e nos institutos interculturais nos Estados Unidos; e v) a modernização dos institutos culturais norte-americanos nos países latino-americanos. Intermediando e executando essas ações, o papel dos embaixadores da boa vontade, como ficaram conhecidos os intelectuais de todas as Américas participantes do programa, foi de fundamental importância para a formação de opinião e a consolidação da 'amizade'.

Em 19 de fevereiro de 1941, Dr. Henry Allen Moe, da Guggenheim Foundation, Dr. Frederick P. Keppel, da Carnegie Corporation, e Dr. David H. Stevens, da Rockefeller Foundation, se uniram voluntariamente em torno da Comissão de Relações Artísticas e Intelectuais Interamericanas. Sob um contrato no valor de cem mil dólares com o Office, concordaram em conduzir um programa de intercâmbio entre professores universitários, acadêmicos e trabaIhadores criativos. ${ }^{19}$ A pesquisa de Inderjeet Parmar (2012) localizou as elites intelectuais dos países-alvos como objetos da filantropia de fundações como a Ford Foundation, Carnegie Endowment e Rockefeller Foundation, desde a Guerra Fria até 11 de setembro de 2001. Apesar de se autodenominarem apolíticas e apartidárias, são elas que vêm tecendo redes globais de intelectuais para consolidar a hegemonia estadunidense por meio da concessão de bolsas de estudos, financiamento para pesquisas e formação de líderes locais.

Archibald MacLeish ${ }^{20}$ e Harry M. Lydenbert, diretor da Biblioteca Pública de Nova York, lideraram um grupo para prestar assessoria ao intercâmbio de livros. ${ }^{21} \mathrm{~A}$ tarefa compreendeu selecionar livros estadunidenses para serem traduzidos para o espanhol e o português e alguns títulos para serem enviados para os países latino-americanos. Fizeram a mesma seleção de livros latino-americanos para serem traduzidos para o inglês (Espinosa, 1976: 172). Com o repasse de 18.500 dólares em 1941 e quase o dobro em 1942 para a Fundação Hispânica, iniciou-se a produção de guias de literatura latino-americana, ${ }^{22}$ enquanto as subcomissões trabalhavam para estabelecer contato com editores comerciais para a publicação das traduções.

Na reunião do Departamento de Estado de setembro de 1941,23 MacLeish apresentou a proposta para a preparação da revista Literary Review, destinada não somente aos intelec-

\footnotetext{
${ }^{19}$ NARA II. RG229, OIAA. Project authorizations, 1942-1945. Letter Archives, Box 533.

${ }^{20}$ Ele era também poeta, dramaturgo, jornalista, professor e advogado. Sua vida pública se iniciou em junho de 1939 com a nomeação para Bibliotecário do Congresso (Winnick, 1983).

${ }^{21} \mathrm{Em} 14$ de novembro de 1940 eles foram nomeados para a Comissão de Literatura por Nelson Rockefeller. NARA II. RG229, OIAA. Department of Press and Publications: Press releases, 1940-1943. Legal Archives, Box 1471.

22 Do investimento de 1941 resultou o guia de James Granier (1942).

${ }^{23}$ NARA II. RG353, Records of Interdepartmental and Intradepartmental Committees (State Department). The interdepartmental committee on cooperation with American Republics. Minutes of meetings, Box 29. Ata da reunião de 17 e 18 set. 1941.
} 
tuais, mas à "classe média alta", sem, contudo, rebaixar o padrão literário (p. 50). 0 objetivo da revista era apresentar:

[...] uma resenha de excelência das artes e das letras, além de refletir a fé dos Estados Unidos na expressão democrática dos homens livres. A revista seria a expressão da natureza do acordo do Novo Mundo, e seus problemas em comum, o que definiria uma área de operação. Ela deveria revelar as Américas reciprocamente e criar uma expressão dinâmica dos espíritos e das vidas dos homens do Novo Mundo (p. 51). ${ }^{24}$

O relatório de Espinosa (1976: 167) já apontara o envolvimento dos acadêmicos e escritores na política de Estado como os "dez por cento que moldaram o destino de outros noventa por cento". Darlene Sadlier (2012: 2), no livro Americans all apontou que a Política da Boa Vizinhança, uma das mais desenvolvidas e intensas da diplomacia cultural, tinha o ambicioso plano de persuadir todas as Américas para a causa da guerra, acionando muitos intelectuais e artistas simpáticos à aliança. A partir das correspondências e relatórios dos membros das comissões, a pesquisadora recompôs a cadeia de ideias que influenciaram Nelson Rockefeller no início de suas atividades no OCIAA. Entre os envolvidos estavam Robert G. Caldwell, Robert M. Hutchins, Quincy Wright, J. Fred Rippy, Harold Lassell, Leonard W. Doob, cada qual sugerindo planos de ações para atingir o maior número de pessoas possível, além das elites intelectuais, uma vez que elas detinham o poder de convencimento e influência das massas.

Assim, o movimento de professores entre as Américas foi intenso entre 1940 e 1948. Quando esses líderes retornavam aos seus respectivos países mostravam um melhor entendimento cultural e uma reação amistosa diante da perspectiva de cooperação hemisférica, apesar das diferentes heranças culturais. Os escritores, historiadores e jornalistas tiveram papel mais prolífico, como era de se esperar. 0 primeiro foi Érico Veríssimo, ${ }^{25}$ romancista e crítico literário, um dos líderes entre os jovens escritores brasileiros. Na filial do Rio de Janeiro exercia o cargo de diretor literário da Livraria do Globo, uma das maiores editoras do sul do Brasil, e em Porto Alegre desempenhava a função de vice-presidente do Instituto Cultural Brasil-Estados Unidos. No seu retorno, Veríssimo registrou suas experiências em Gato preto em campo de neve, dedicado a Thornton Wilder, publicado ainda em 1941, na sua décima edição em 1976 (cf. Espinosa, 1976: 295-303).

\footnotetext{
${ }^{24}$ Minha tradução de: "truly excellent review of arts and letters which should also reflect the United States faith in the democratic expression of free men. It would express an agreement as to the nature of the New World, its common problems - and would define the area of common operation. It would discover the Americas to each other and create a dynamic expression of the spirit and lives of the men of the New World."

${ }^{25}$ Para maiores detalhes sobre o papel de Erico Verissimo na política interamericana cf. Minchillo (2015).
} 


\section{UM BRASIL AGRÁRIO EM CONTRASTE COM A INDUSTRIALIZAÇÃO DOS EUA}

interpretação de William Graebner (1990: 2) da cultura dos EUA nos anos 1940 sin-
tetiza bem o campo literário: "a cultura americana foi definitivamente democrática, pelo menos na superfície". Os pronunciamentos, os cartazes, as reportagens, as entrevistas, o cinema e a publicidade do OCIAA incorporavam o lema da união não somente dos estadunidenses, mas também hemisférica. Consciente ou inconscientemente, a preferência de editores por histórias ou conjuntos de histórias que representassem a democracia reforçaria o lema da união, ao mesmo tempo em que responderia aos anseios do público por histórias que representassem seus valores e ideais, mesmo que estes fossem superficiais e voláteis.

Agregou-se o princípio da 'liberdade de expressão' à produção cultural estadunidense, tornando-a um 'produto' de exportação e sedução. A aceitação de material brasileiro para publicação também foi incorporada no âmbito da mesma premissa, e até os escritores simpatizantes das ideias comunistas tiveram suas vozes traduzidas para o inglês. 0 fato desdobra o cenário propagandístico da superioridade de um país onde a democracia estaria acima de tudo, mostrando-se aberto a quaisquer opiniões vindas de segmentos ideológicos diversos, mas que, na realidade, dissimulava outra prática: o impedimento da tradução de escritores de opiniões favoráveis aos regimes fascista e nazista na Europa, e, no caso brasileiro, dos grupos ligados aos integralistas. Além disso, cessado o conflito militar, iniciou-se a Guerra Fria, e os intelectuais comunistas também passaram a ser vetados pelo establishment dos Estados Unidos.

O controle ideológico do OCIAA moldou e definiu o padrão estético do cânone brasileiro para a tradução levando em conta muito mais a posição política de seus escritores que a qualidade estética de seus trabalhos. 0 crescente envolvimento de escritores brasileiros como representantes da voz popular durante o Estado Novo facilitou a escolha desses textos atendendo aos fins didáticos do OCIAA, pois o projeto literário de vários romances brasileiros já conciliava a função estética com o político-pedagógico, ou seja, a ideia de mostrar o Brasil para os brasileiros. Vislumbrou-se a tradução em inglês como ferramenta para inflamar o interesse coletivo em construir a brasilidade. Porém essa ambição não foi forte o suficiente para enfrentar a poderosa máquina de guerra estadunidense, que já conseguira se apropriar dos traquejos para o trânsito na burocracia do DIP e despejava toneladas de material para a disseminação dos princípios do American dream. Gradualmente, os brasileiros rendiam-se aos produtos e à cultura estadunidense, com suas máquinas, indústrias e filmes, muito mais sedutoras que a brasilidade que vinha sendo construída pelos intelectuais. Resumindo, exportou-se 
a imagem de um Brasil em vias de modernização e importaram-se valores do modo de vida estadunidense, minando e expondo as contradições do próprio conceito de brasilidade que se pretendia construir.

O OCIAA elegeu textos que mostrassem 'o modo de vida brasileiro' e a diversidade regional. Em se tratando de representação, tem-se o seguinte quadro para os livros traduzidos: Terras do sem fim e A fogueira, que representariam o deslocamento de pessoas e o desbravamento do interior para a formação de novas cidades, muito próximos do romance social proletário de 1930 dos Estados Unidos à moda de John Steinbeck; O resto é silêncio, Caminhos cruzados e Olhai os lírios do campo, como a representação do romance urbano e das diversas classes sociais que constituíam as cidades, também em consonância com o cânone doméstico; Inocência, resgatado do século XIX para representar o regionalismo romântico ambientado no Mato Grosso; Os Sertões, a narrativa da Guerra de Canudos, considerada por muitos críticos à época como um retrato do Brasil profundo. E para equilibrar o regionalismo preponderante nos títulos anteriores, foi importante incluir pelo menos um livro com uma temática mais universal como Angústia, que não deixa de reafirmar a narrativa do 'fluxo de consciência', também sendo produzida nos Estados Unidos por escritores como William Faulkner e Ernest Hemingway, por exemplo.

Além da escolha de obras com características 'regionalistas' produzidas por escritores mais contemporâneos, os holofotes voltaram-se para uma obra do início do século XX, Os Sertões, de Euclides da Cunha, que, segundo Velloso (1987), fora resgatada pelos intelectuais do Estado Novo como o clássico que incorporava o espírito de brasilidade e os destinos da nacionalidade, expressos por meio de uma linguagem brasileira que traduzia a força da terra. 0 engajamento para a construção da brasilidade, função atribuída à literatura pelos intelectuais do Estado Novo, trouxe à cena a cisão entre o litoral e o sertão. Segundo Cassiano Ricardo, um dos pioneiros do movimento verde-amarelo, os representantes dessa dicotomia foram Machado de Assis e Euclides da Cunha. 0 primeiro, ao expressar o cosmopolitismo litorâneo em seus trabalhos, incorporava a influência estrangeira nas letras, enquanto Euclides da Cunha, ao revelar o sertão profundo, mostrava o verdadeiro Brasil, a crua realidade do mundo rural, sem pinceladas estrangeiras que escondessem o real espírito da brasilidade (Velloso, 1987). A designação enfática de Os Sertões como a representação de brasilidade nas décadas de 1930 e 1940, em contraposição ao cosmopolitismo de Machado de Assis, explica em parte o fato de a obra machadiana só ter sido traduzida nos Estados Unidos a partir da década de 1950. Vários dos seus romances já haviam sido traduzidos para o francês, o espanhol e o italiano nas décadas que precederam a Guerra, mas só se tornaram conhecidos para o público falante de língua inglesa a partir do marco da Boa Vizinhança. 
Os textos brasileiros traduzidos nos anos 1940, apesar de algumas semelhanças com o cânone estadunidense do período, distanciam-se dele no plano estético e na temática social exclusivamente externa, com exceção de Angústia, de Graciliano Ramos. As inquietações sociais que predominaram no cânone estadunidense entre os anos 1920 e 1930 se moviam cada vez mais em direção às aflições individuais e focavam nas inquietudes psicológicas na década de 1940 (deslocamento também presente na cena literária brasileira na década de 1930 segundo a análise de Luís Bueno, 2006). O OCIAA favoreceu os livros que representassem o ambiente externo brasileiro (e latino-americano) para a demanda de um público que procurava se instruir sobre os países aliados. Um cenário diferente se instala quando escritores, agenciadores ou editores de diferentes países entram em contato devido a interesses em comum, pois há geralmente uma preferência por textos inovadores para oxigenar os cânones domésticos. No caso do projeto tradutório, esse contato estreitamente vinculado a interesses políticos forjou um cânone de realismo social, preterindo a estética psicológica. Esse movimento fortaleceu a tradição canônica estadunidense das décadas anteriores, e introduziu um elemento inovador, a temática geográfica.

Ampliando-se o mapa das Américas para observar os títulos da ficção latino-americana traduzida ou premiada nos EUA, nota-se que os romances emulam um universo agrário e hostil no qual o homem latino-americano supostamente se encontrava. Sem muitas perspectivas de melhoria ou desenvolvimento devido às condições geográficas de isolamento e imobilidade em um clima desértico, de mata cerrada ou de áreas alagadiças, esses romances representariam, mesmo que superficialmente, o contraste com o progresso urbano e a industrialização nos Estados Unidos. Nestes termos, a liderança hemisférica estadunidense, daquele momento em diante, fazia-se mais do que necessária e justa.

Se houve uma intenção do governo estadunidense, esta convergiu com os interesses do governo brasileiro de então, apoiado por intelectuais de vários segmentos, que tiveram participação ativa e crucial no sentido de possibilitar o movimento pan-americano e a 'americanização' do brasileiro médio. A partir daí, as posições políticas individuais, as decisões tomadas no 'calor' do momento (o contexto da Segunda Guerra Mundial), aliadas ao fator de sobrevivência do artista foram os fatores que atravessaram, circundaram e deixaram múltiplas marcas nos acontecimentos da cena literária brasileira.

Elevados recursos financeiros e trabalho foram investidos para montar uma estrutura com discursos afinados e ações sistematizadas para um esforço bélico. Nos anos 1940, a tradução da literatura brasileira foi apropriada por um projeto cultural do Departamento de Estado dos Estados Unidos com objetivo "instrutivo". Somente mais tarde é que o interesse pela literatura se desenvolveu de acordo com as demandas dos institutos ou departamentos de estudos latino-americanos. 


\section{REFERÊNCIAS BIBLIOGRÁFICAS}

AMADO, Jorge. Terras do sem fim. 1a ed. São Paulo: Livraria Martins Editora, 1943.

The violent land. Trad. Samuel Putnam. 1a ed. New York: Alfred Knopf, 1945.

BUENO, Luís. Uma história do romance de 30. 1ª ed. São Paulo: EDUSP, 2006.

CARNEIRO, Cecílio. The bonfire. Trad. Dudley Poore. 1a ed. New York: Farrar and Rinehart, 1944.

CRULS, Gastão. The mysterious Amazonia. Trad. Joseph Sadler. 1a ed. Rio de Janeiro: Livraria-Editora Zelio Valverde, 1944.

CUNHA, Euclides da. Rebellion in the backlands. Trad. Samuel Putnam. 1a ed. Chicago: University of Chicago Press, 1944.

ESPINOSA, J. Manuel. Inter-American beginnings of U.S. cultural diplomacy (1936-1948). 1a ed. Washington DC: Department of State Publications, 1976.

FLORES, Angel; POORE, Dudley (ed.). Fiesta in November. 1 ed. Boston, MS: Houghton Mifflin Company, 1942.

GRAEBNER, William. The age of doubt. 1a ed. Boston: Twayne Publishers, 1990.

GRANIER, James A. Latin American belles-lettres in English translation - a selective and annotated guide. Washington DC: Library of Congress, 1942.

GUERRANT, Edward O. Roosevelt's Good Neighbor Policy. 1a ed. Albuquerque: University of New Mexico Press, 1950.

HIRSCH, Irene. Versão brasileira: traduções de autores de ficção em prosa norte-americanos do século XIX. 1a ed. São Paulo: Alameda Casa Editorial, 2006.

KLÖCKNER, Luciano. O Repórter Esso: a síntese radiofônica mundial que fez história. 1a ed. Porto Alegre: EDIPUC, 2008.

MILTON, John. O Clube do Livro e a tradução. 1a ed. Bauru: EDUSC, 2001.

MINCHILLO, Carlos Cortez. Érico Veńssimo, escritor do mundo. 1ạ ed. São Paulo: EDUSP, 2015.

MOURA, Gerson. Tio Sam chega ao Brasil: a penetração cultural americana. 1a ed. São Paulo: Brasiliense, 1984.

OLIVEIRA, Laura de. Guerra Fria e política editorial: a trajetória das Edições GRD e a campanha anticomunista dos Estados Unidos no Brasil (1956-1968). 1ae ed. Maringá: EDUEM, 2015.

PAES, José Paulo. Tradução: a ponte necessária. 1a ed. São Paulo: Ática, 1990.

PARMAR, Inderjeet. Foundations of the American century. 1a ed. Nova York: Columbia University Press, 2012.

RAMOS, Graciliano. Anguish. Trad. Louis Kaplan. 1a ed. New York: Alfred Knopf, 1946.

ROSTAGNO, Irene. Searching for recognition: the promotion of Latin American literature in the United States. $1^{\text {a }}$ ed. Westport: Greenwood Press, 1997.

SADLIER, Darlene Joy. Americans all. 1ae ed. Texas: University of Texas Press, 2012.

TAUNAY, Visconde de. Inocência. Trad. Henriqueta Chamberlain. 1aㅡ ed. New York: Macmillan Company, 1945. 
TOTA, Antonio Pedro. O imperialismo sedutor: a americanização do Brasil na época da Segunda Guerra. 1a ed. São Paulo: Companhia das Letras, 2000.

UNITED STATES. Office of the Coordinator of Inter-American Affairs. Activities of the CIAA in Brazil. Washington DC: US Government Printing Office, 1943.

VELLOSO, Mônica Pimenta. Os intelectuais e a política cultural do Estado Novo. Rio de Janeiro: Fundação Getúlio Vargas/CPDOC, 1987. Disponível em: <http://bibliotecadigital.fgv.br/dspace/bitstream/handle/10438/6604/803.pdf? sequence=1 $>$. Acesso em: 10 dez. 2014.

VERÍSSIMO, Érico. Consider the lilies of the field. Trad. Jean Karnoff. 1a ed. New York: Macmillan Company, 1947.

Crossroads. Trad. Louis Kaplan. 1e ed. New York: Macmillan Company, 1943.

The rest is silence. Trad. Louis Kaplan. 1ae ed. New York: Macmillan Company, 1943.

WINNICK, R. H. (ed.). Letters of Archibald MacLeish (1907-1982). 1a ed. Boston: Houghton Mifflin Company, 1983. 